\title{
Central Macular Thickness: A Comparative Study of Diabetics Vs Healthy
}

\author{
Beenish Khan, Muhammad Muneer Quraishy, Asma Shams
}

Pak J Ophthalmol 2019, Vol. 35, No. 1

See end of article for authors affiliations

Correspondence to:

Beenish Khan

Assistant Professor

Department of Ophthalmology

United Medical and Dental

College, Creek General

Hospital, Korangi, Karachi

Email:

beenish_aquarian@hotmail.com
Purpose: To compare the central macular thickness amongst diabetics with that of healthy population by using Optical Coherence Tomography.

Study Design: Case control study.

Place and Duration of Study: Department of Ophthalmology Unit I, Civil Hospital Karachi from $5^{\text {th }}$ March 2012 to $4^{\text {th }}$ September 2012.

Material and Methods: We randomly selected patients with diabetes (cases) and healthy patients (control) with clinically normal macula and no diabetic retinopathy. Detailed relevant history was acquired. Best corrected visual acuity (BCVA) was measured with standard Snellen's chart. Detailed dilated fundus examination was done using $+90 \mathrm{D}$ and $+78 \mathrm{D}$ lens. Central macular thickness within an area of $1000 \mu \mathrm{m}$ was measured using Optical Coherence Tomography.

Results: There were 68 patients in each group. The mean age of patients in the Diabetic group was $47.94 \pm 14(20-80)$ years and in the healthy group it was found to be $39.53 \pm 14.93(20-80)$ years. Out of these 26 were male and 42 were female in the diabetic group whereas 27 were male and 41 were female in the healthy group. Mean central macular thickness of Diabetic eyes were $214.48 \pm$ $31.41 \mu \mathrm{m}$ and that of healthy eyes were $236.79 \pm 19.38 \mu \mathrm{m}$ with mean difference of $22.31 \pm 4 \mu \mathrm{m}$ ( $p$ value $=0.000)$.. A statistically significant difference in the central macular thickness of Diabetics and healthy patients was observed.

Conclusion: The central macular thickness is significantly decreased in eyes of patients with Diabetes.

Keywords: Central macular thickness, Optical Coherence Tomography, OCT, Diabetic Retinopathy, Diabetic Maculopathy.
$\mathrm{D}$ iabetes mellitus is a multifactorial disease which can lead to multiple organ dysfunction. Diabetic retinopathy including diabetic maculopathy is one of the complications of diabetes mellitus which leads to the sight threatening consequences. Diabetic maculopathy is the most prevalent sight threatening condition in diabetes ${ }^{1}$.

Conventional methods of evaluating macular thickness like slit lamp biomicroscopy and stereo fundus photography are relatively insensitive to small changes in retinal thickness. Thus for measuring retinal thickness quantitatively several new techniques have been explored ${ }^{2}$. Retinal imaging techniques can provide detailed cross sectional information which can be complementary to conventional fundus photography and fluorescein angiography ${ }^{3}$.

Optical coherence tomopgraphy (OCT) is a new medical diagnostic imaging technology which can perform cross sectional or tomographic imaging of biological tissues in micrometer resolution ${ }^{4}$. Its application has been demonstrated in normal human eyes with certain macular abnormalities and glaucoma ${ }^{3,5,6}$.

Despite normal findings in slit lamp biomicroscopy early changes in the retinal thickness 
can be detected by optical coherence tomography ${ }^{7}$ and it has been observed that a greater than $10 \%$ change in baseline macular thickness by optical coherence tomography is considered significant ${ }^{8}$. Macular thickness measurements may be used to assess disease, monitor its progress and evaluate treatment ${ }^{9}$. Macular thickness has been shown to be increased in diabetics with clinically normal macula ${ }^{10}$.

The Macular thickness measurement may differ with the population. Thus it is desirable that measurements derived from the normative population be as close as possible to the population for which the instrument is to be used ${ }^{11}$.

It has been observed that strict diabetes control slowed down the appearance of diabetic retinopathy and can play an important part in protection of macula ${ }^{12-13}$.

The rationale of our study is to ascertain whether there is any difference in the macular thickness of normal with diabetics with clinically normal maculae in Pakistani population, so that early diagnosis can be made. This will ensure that strong check on the diabetes control is maintained and proper treatment can be applied at proper time before the appearance of sight threatening complications.

\section{MATERIAL AND METHODS}

We randomly selected patients with diabetes (cases) and healthy patients (control) with clinically normal macula and no diabetic retinopathy attending the Ophthalmology out patients department of Unit I, Civil Hospital Karachi from 5th March 2012 to $4^{\text {th }}$ September 2012.

Healthy patients included in the study had a best corrected Visual acuity of 6/6, no associated ocular co morbidity, no history of previous ocular surgery or laser therapy, no history of systemic disorder that can effect eye and no history or evidence of pathology

Table 1: Base Line Characteristics.

\begin{tabular}{|c|c|c|c|c|}
\hline & & $\begin{array}{l}\text { Controls } \\
\text { (Healthy) }\end{array}$ & $\begin{array}{c}\text { Cases } \\
\text { (Diabetics) }\end{array}$ & $P$ value \\
\hline \multicolumn{2}{|l|}{ No. of Eyes } & 136 & 136 & \multirow{4}{*}{$\begin{array}{l}0.47^{*} \\
0.86^{* *}\end{array}$} \\
\hline \multicolumn{2}{|l|}{ Age (years) } & $47.94 \pm 14.07$ & $39.52 \pm 14.93$ & \\
\hline Gender & Males & $27(39.7 \%)$ & $26(38.2 \%)$ & \\
\hline No. (\%) & Females & $41(60.3 \%)$ & $42(61.8 \%)$ & \\
\hline \multicolumn{2}{|c|}{ Mean CMT $(\mu \mathrm{m})$} & $236.79 \pm 19.38$ & $214.48 \pm 31.41$ & $0.00^{*}$ \\
\hline
\end{tabular}

*Independent Sample T Test features of retina.

Diabetic patients included in the study had established diabetes and were using insulin or oral hypoglycemic agents either controlled or uncontrolled as detected by $\mathrm{HbA1c}$. The duration of diabetes was more than 5 years. There were no signs of diabetic maculopathy clinically.

The null hypothesis made was made that there is no difference in macular thickness between diabetics with clinically normal macula and healthy individuals. It was a case control study with a sample size of 136 eyes in each group. Sampling technique used was non probability purposive sampling.

All subjects who fulfilled the criteria of Healthy and Diabetic subjects, subjects of either gender, subjects ranging from $20 \mathrm{yrs}-80 \mathrm{yrs}$ age and duration of diabetes greater than $5 \mathrm{yrs}$ were included in the study.

Patients having proliferative diabetic retinopathy or advance diabetic eye disease, ocular comorbidities other than diabetic retinopathy like ARMD, retinal dystrophy, glaucoma etc., history of previous ocular surgery or laser therapy and subjects in whom scans with signal strength $\leq 60$ could not obtained on OCT were excluded from the study.

Subjects selected from the outpatient department of civil hospital Karachi underwent slit lamp examination including +90D and +78D lens examination after dilatation with $1 \%$ tropicamide. We included 136 healthy eyes that fulfilled the selection criteria. There were 136 diabetic eyes with established diabetes, using insulin or oral hypoglycaemic agents since $\geq 5$ yrs that were selected. An informed consent was taken after explaining the whole procedure. Refraction and Fundus flourescein angiography of all patients was done to control effect modifying. All included subjects underwent scanning with a Spectral Domain Optical Coherence tomography (SD OCT) device (3D OCT 1000 Topcon Japan) by one designated experienced person. Follow up of the patient was not required.

For quantitative evaluation, the thickness of the central circular area of 1000 micrometers in diameter was used as defined by the early treatment diabetic retinopathy study (ETDRS). ${ }^{14}$ Statistical Packages for Social Science (SPSS16) was used to analyze data. Mean was calculated for quantitative variables (central macular thickness 
and age). Frequency and percentage was used for qualitative variables like gender. Independent sample $t$ test was used to see the difference between the two groups i.e. diabetic and healthy.

$\mathrm{P} \leq 0.05$ was considered significant.

We stratified the data in multiple groups according to age, gender, diabetic control, and duration of diabetes. Then we calculated through chi square for both groups to see the effect of each variable accordingly.

Age stratification was done decade wise and 7 groups were made. Group 1; 20-29 years, group 2; 30-39 years, group 3; 40-49 years, group $4 ; 50-59$ years, group $5 ; 60-69$ years, group 6; 70-79 years and group $7 ; 80$ years.

Patients were stratified in 2 groups according to glycemic control. Group 1; controlled diabetes, group 2; uncontrolled diabetes.

Patients were stratified according to duration of diabetes in 5 groups. Group 1; 5-10 years, Group 2; 11-15 years, Group 3; 16-20 years, Group 4 ; $21-25$ years.

\section{RESULTS}

There were 68 subjects in each group. Table 1 details the characteristics of both the groups. Statistically significant difference was found with respect to age in healthy group $(\mathrm{p}=0.038)($ Table 3$)$ but not in diabetic group $(\mathrm{p}=0.669)$ (Table 2). The two groups had statistically insignificant variations with respect to gender $(\mathrm{p}=0.86)$ (Table $1 \& 4$ ), duration of diabetes $(\mathrm{p}=0.311)$ (Table 6) and type of Diabetes $(p=0.72)$ (Table 5). All patients had controlled diabetes.

The mean central macular thickness in the control group was $236.79 \pm 19.38 \mu \mathrm{m}$ which was
Table 2: Effect of Age on CMT in Diabetic patients.

\begin{tabular}{|cccc|}
\hline $\begin{array}{c}\text { Age of the Patients } \\
\text { in Groups }\end{array}$ & $\begin{array}{c}\text { No. of } \\
\text { Cases }\end{array}$ & Mean CMT & P value \\
\hline $20-29$ yrs & 11 & $206.27 \pm 28.69$ & \\
$30-39$ yrs & 3 & $217.67 \pm 50.52$ & \\
$40-49$ yrs & 14 & $219.14 \pm 28.09$ & \\
$50-59$ yrs & 28 & $210.93 \pm 34.94$ & $0.669^{*}$ \\
$60-69$ yrs & 8 & $218.62 \pm 29.07$ & \\
$70-79$ yrs & 4 & $235.00 \pm 11.43$ & \\
Total & 68 & & \\
\hline
\end{tabular}

*One Way Anova

Table 3: Effect of Age on CMT in Healthy subjects.

\begin{tabular}{|cccc|}
\hline $\begin{array}{c}\text { Age of the Patients in } \\
\text { Groups }\end{array}$ & No. of Cases & Mean CMT & P value \\
\hline $20-29$ yrs & 19 & $240.62 \pm 20.27$ & \\
$30-39$ yrs & 18 & $224.83 \pm 18.78$ & \\
$40-49$ yrs & 15 & $240.40 \pm 16.55$ & \\
$50-59$ yrs & 8 & $251.50 \pm 10.85$ & $0.038^{*}$ \\
$60-69$ yrs & 5 & $234.80 \pm 23.91$ & \\
$70-79$ yrs & 1 & N/A & \\
80 yrs & 2 & $232.50 \pm 3.53$ & \\
Total & 68 & & \\
\hline
\end{tabular}

*One Way Anova

Table 4: Effect of Gender on CMT.

\begin{tabular}{|lccc|}
\hline & \multicolumn{2}{c}{ Gender } & P value* $^{*}$ \\
\hline CMT Control & $245.59 \pm 15.25$ & Female & \\
CMT Case & $214.19 \pm 34.69$ & $214.00 \pm 19.77$ & 0.086 \\
\hline
\end{tabular}

*Independent Samples T test.

Table 5: Effect of Type of Diabetes on CMT.

\begin{tabular}{|lccc|}
\hline Type of Diabetes & Total no of Cases & Mean CMT & P value $^{*}$ \\
\hline IDDM & 13 & $211.69 \pm 27.92$ & 0.72 \\
NIDDM & 55 & $215.15 \pm 32.38$ & \\
\hline
\end{tabular}

*Independent Sample T Test

Table 6: Effect of Duration of Diabetes on CMT.

\begin{tabular}{|lcrc|}
\hline Duration of Diabetes & No. of cases & Mean CMT & P value $^{*}$ \\
\hline $5-10$ yrs & 37 & $221.13 \pm 33.16$ & \\
$11-15$ yrs & 19 & $206.84 \pm 25.26$ & \\
$16-20$ yrs & 8 & $213.50 \pm 27.29$ & 0.189 \\
$21-25$ yrs & 4 & $214.48 \pm 40.46$ & \\
Total num of cases & 68 & & \\
\hline
\end{tabular}

*One Way Anova test 
significantly thicker than the value of $214.48 \pm 31.41$ $\mu \mathrm{m}$ obtained for the case group $(\mathrm{p}=0.00)$. The mean central macular thickness in the cases group was thinner by $22.31 \pm 4.47 \mu \mathrm{m}$ as compared to the control group $(p=0.00)$. Thus the decreased CMT in Diabetic group showed a significantly thinner mean CMT even in the absence of clinical maculopathy.

\section{DISCUSSION}

Optical Coherence Tomography is considered as a useful tool for the measurement of retinal thickness. It raises the probability of correct diagnosis, helps in following the disease progression as well as monitoring the efficacy of treatment given for diabetic retinopathy ${ }^{15}$. That is the reason we have chosen diabetic patients with normal maculae so that we find earliest changes that are not evident in other ways.

We included 68 diabetic cases with no maculopathy and compared them with that of normal. The mean age of diabetic patients was $39.52 \pm 14.93$ years and that of healthy group was $47.94 \pm 14.07$ years.

Our study showed that the mean central macular thickness of the diabetic patients came out to be 214.48 \pm 31.41 which is thinner than the mean central macular thickness of the healthy cases $236.79 \pm 19.38 \mu \mathrm{m}$ (p 0.000). In 2013, a same study was done in Turkey also revealing decreased macular thickness in diabetics $(227.19 \pm 29.94 \mu \mathrm{m}$ in healthy as compare to $232.12 \pm$ $24.41 \mu \mathrm{m}$ in diabetics) ${ }^{16}$. Murugesan $\mathrm{S}^{17}$, and Jiang jing et $\mathrm{al}^{18}$ also found decreased central macular thickness in clinically normal diabetic maculae in comparison to that of healthy individuals. Statistically significant pericentral retinal thinning has also been demonstrated by Biallosterski and co-workers ${ }^{19}$, when they compared the retinal thicknesses of diabetics and healthy individuals, supporting the hypothesis of nerve tissue cell loss in the initial stages of diabetic retinopathy. In addition to this study by Nilsson et al ${ }^{20}$ also upholds our study result by demonstrating decreased retinal thickness in diabetic patients with early or no diabetic retinopathy.

Pre-clinical retinal nerve fiber layer thickness is also found to be less in the superior quadrant and other areas of retina in diabetic patients in comparison to the healthy retina ${ }^{21}$. All of these studies suggest damage to the neural tissue in diabetes which involves mostly the ganglion cell layer and inner plexiform layer ${ }^{22}$.

Certain factors were observed in healthy eyes also that can directly or indirectly impact the measured central macular thickness on OCT. These include ethnicity and gender of the subject ${ }^{23-24}$. In our study we didn't find any significant difference in central macular thickness with respect to gender. Eriksson and $\mathrm{Alm}^{25}$ reported negative relationship between retinal thickness and age for all ETDRS areas, total macular volume and RNFL thickness in healthy individuals (Retinal thickness decreased by $0.26-0.46$ $\mathrm{mm}$, macula volume $0.01 \mathrm{~mm} 3$ and RNFL $0.09 \mathrm{~mm}$ per year). In our study significant difference was found in CMT with respect to age in healthy groups but no definite pattern was found. There was no significant difference in the macular thickness of diabetic group according to the age.

Overall, we found the following findings: significant decreased central macular thickness of diabetics vs. healthy in normal maculae, no specific pattern of macular thickness was found according to the age, no specific pattern of macular thickness was found according to duration of diabetes. One limitation to our article was decreased sample size which was total of 136 eyes in both groups

\section{CONCLUSION}

Since p-value is significant (0.000) therefore null hypothesis is rejected and we come to the conclusion that the macular thickness of diabetic patients is less than that of healthy individual even when there is no clinical evidence of any changes. This study suggests that there are certain changes that occur during the course of diabetes which lead to the retinal damage and resultant decreased thickening.

\section{Author's Affiliation}

Dr. Beenish Khan

Assistant Professor

Department of Ophthalmology

United Medical and Dental College

Creek General Hospital

Korangi, Karachi

Dr. Muhammad Muneer Quraishy

Professor of Ophthalmology

Dow University of Health Sciences

Civil Hospital Karachi

Dr. Asma Shams

Senior Registrar Ophthalmology

Shaheed Mohtarrma Benazir Bhutto Medical College Liari 


\section{Author's contribution}

Dr. Beenish Khan

Manuscript writing, data collection, analysis and interpretation.

Dr. Muhammad MuneerQuraishy

Study concept and design.

Dr. Asma Shams

Manuscript review.

\section{REFERENCES}

1. Klein R, Klein BE, Moss SE, Davis MD, De Mets DL. The Wisconsin epidemiologic study of diabetic retinopathy IV. Diabetic macular edema. Ophthalmol. 1984; 91: 1464-74.

2. Nussenblat RB, Kaufman SC, Palestine AG, Davis MD, Ferris FL. Macular thickening and visual acuity. Ophthalmology 1987; 94: 1134-9.

3. Hee MR, Puliafito CA, Duker JS, Reichel E, Coker JF, Wilkins JR et al. Topography of diabetic macular edema with optical coherence tomography. Ophthalmol. 1998; 105: 360-70.

4. Chauhan DS, Marshall J. The interpretation of optical coherence tomography images of the retina. Invest Ophthalmol Vis Sci. 1999; 40: 2332-42.

5. Koozekanani D, Roberts C, Katz SE, Herderick ED. Intersession repeatability of macular thickness measurements with the Humphrey 2000 OCT. Invest Ophthalmol Vis Sci. 2000; 41: 1486-91.

6. Munuera JM, Garcia-Layana A, Maldonado MJ, Aliseda D, Moreno- Montanes J. Optical coherence tomography in successful surgery of vitreo-macular traction syndrome. Arch Ophthalmol. 1998; 116: 1388-9.

7. Tocino HS, Vidal AA, Maldonado MJ, Montanes JM, Layana AG. Retinal thickness study with optical coherence tomography in patients with diabetes. Invest Ophthalmol Visual Sci. 2002; 43: 1588-94.

8. Browning DJ, Fraser CM, Propst BW. The variation in optical coherence tomography-measured macular thickness in diabetic eyes without clinical macular edema. Am J Ophthalmol. May 2008; 145 (5): 889-93.

9. Workman HL, Hosking SL. Repeatability and reproducibility of macular thickness measurements using OCT 3 system in normal subjects and diabetics patients. Invest Ophthalmol Visual Sci. 2004; 45: 2378B13.

10. Emerah SH, Labib HM, Farag MY, Kamel HF. Macular thickness measurements in diabetic patients without diabetic retinopathy using optical coherence tomography. J Am Sci. 2011; 7 (11): 223-7.

11. Tewari HK, Wagh VB, Sony $\mathbf{P}$, Venkatesh $\mathbf{P}$, Singh $\mathbf{R}$. Macular thickness evaluation using the optical coherence tomography in normal Indian eyes. Ind J Ophthalmol. 2004; 52 (3): 199-204.
12. Peng YJ, Tsai MJ. Impact of metabolic control on macular thickness in diabetic macular oedema. Diab Vasc Dis Res. 2018; 15 (2): 165-8.

13. Teberik K, Eski MT, Kaya M. Associations of glycated hemoglobin (HbA1c) level with central corneal and macular thickness in diabetic patients without macular edema, 2018; 4 (4): 294-9.

14. Early treatment diabetic retinopathy study research group. Photocoagulation for diabetic macular edema. ETDRS report number 1. Arch Ophthalmol. 1985; 103: 1796-806.

15. Hannouche RZ, Avila MP. Retinal thickness measurement and evaluation of natural history of the diabetic macular edema through optical coherence tomography. Arq Bras Oftalmol. 2009; 72 (4): 433-8.

16. Demir M, Dirim B, Acar Z, Yilmaz $M$ and Sendul Y. Central Macular Thickness in Patients with Type 2 Diabetes Mellitus without Clinical Retinopathy. J Ophthalmol, 2013.

17. Murugesan S, Jha K N, Krishnagopal S and Ezhumalai G. Central macular thickness in diabetics without retinopathy. TNAO J Ophthalmic Sci \& Research, 2018; 56 (3): 150-4.

18. Jiang J, Liu Y, Chen Y, Ma B, Qian Y, Zhang Z et al. Analysis of Changes in Retinal Thickness in Type 2 Diabetes without Diabetic Retinopathy. J Diabetes Research, 2018.

19. Biallosterski C, van Velthoven ME, Michels RP et al. Decreased optical coherence tomography-measured pericentral retinal thickness in patients with diabetes mellitus type 1 with minimal diabetic retinopathy. Br J Ophthalmol. 2007; 91 (9): 1135-8.

20. Nilsson M, Wendt G, Wanger P, Martin L. Early detection of macular changes in patients with diabetes using Rarebit Fovea Test and optical coherence tomography. Br J Ophthalmol. 2007; 91 (12): 1596-8.

21. Peng HP, Lin HS, Lin S. Nerve fibre layer thinning in patients with preclinical retinopathy. Can J Ophthalmol. 2009; 44 (4): 417-22.

22. Cabrera BD, Somfai GM. Early detection of retinal thickness changes in diabetes using Optical Coherence Tomography. Med Sci Monit. 2010; 16 (3): 15-21.

23. Kelty PJ, Payne JF, Trivedi RH, Kelty J, Bowie EM, Burger BM. Macular thickness assessment in healthy eyes based on ethnicity using stratus optical coherence tomography. Invest Ophthalmol Visual Sci. 2008; 49: 2668-72.

24. Ooto S, Hangai M, Sakamoto A, Tomidokoro A, Araie M, Otani T, et al. Three-dimensional profile of macular retinal thickness in normal Japanese eyes. Invest Ophthalmol Visual Sci. 2010; 51: 465-73.

25. Eriksson U, Alm A. Macular thickness decreases with age in normal eyes: a study on the macular thickness map protocol in the Stratus OCT. Br J Ophthalmol. 2009; 93: $1448-52$. 